\title{
Cultural and morphological variations among the isolates of Sclerotinia sclerotiorum (Lib.) de Bary causing Sclerotinia stem rot
}

\author{
DEVESH PATHAK*, R.U. KHAN AND VAIBHAV PRATAP SINGH
}

Department of Plant Protection, Faculty of Agricultural Sciences, Aligarh Muslim University, ALIGARH (U.P.) INDIA

\section{ARITCLE INFO}

Received : 10.04 .2017

Revised : 13.08 .2017

Accepted : 25.08.2017

\section{KEY WORDS :}

Sclerotinia sclerotiorum, Isolates, Cultural, Morphological variations

*Corresponding author: devpathak58@gmail.com

\begin{abstract}
Sclerotinia stem rot caused by Sclerotinia sclerotiorum (Lib.) de Bary is one of the most serious and damaging disease of many important crops and weeds worldwide. It causes considerable yield losses in quality and quantity of crop produce. In present study, Eleven isolates of Sclerotinia sclerotiorum were collected from different host plants and studied for their cultural and morphological variations. The observations of study revealed that all isolates varied in their cultural characters viz., colony growth $(\mathrm{mm})$, colony appearance (colour and type of growth) and morphological characters viz., initiation, size and number of sclerotia. Among different isolates, carrot isolate $(75.86 \mathrm{~mm})$ was found significantly fast growing followed by brinjal isolate $(70.96 \mathrm{~mm})$, while potato isolate $(57.13 \mathrm{~mm})$ grown slowly in potato dextrose agar medium at 72 hours after inoculation. Maximum number of sclerotia (34.66) was produced in tomato isolate, whereas, minimum (4.33) in parthenium isolate. Largest size of sclerotia (9x4.66 $\mathrm{mm})$ was observed in tomato isolate however, smallest size of sclerotia $(2.0 \times 2.0 \mathrm{~mm})$ were produced in lentil and parthenium isolates.
\end{abstract}

How to view point the article : Pathak, Devesh, Khan, R.U. and Singh, Vaibhav Pratap (2017). Cultural and morphological variations among the isolates of Sclerotinia sclerotiorum (Lib.) de Bary causing Sclerotinia stem rot. Internat. J. Plant Protec., 10(2) : 295-298, DOI : 10.15740/ HAS/IJPP/10.2/295-298. 